This item was submitted to Loughborough's Research Repository by the author.

Items in Figshare are protected by copyright, with all rights reserved, unless otherwise indicated.

\title{
Mechanical and electrical characterisation of individual ACA conductor particles
}

PLEASE CITE THE PUBLISHED VERSION

PUBLISHER

(C) IEEE

VERSION

VoR (Version of Record)

LICENCE

CC BY-NC-ND 4.0

\section{REPOSITORY RECORD}

Dou, Guangbin, David C. Whalley, and Changqing Liu. 2019. "Mechanical and Electrical Characterisation of Individual ACA Conductor Particles". figshare. https://hdl.handle.net/2134/4195. 
This item was submitted to Loughborough's Institutional Repository (https://dspace.lboro.ac.uk/) by the author and is made available under the following Creative Commons Licence conditions.

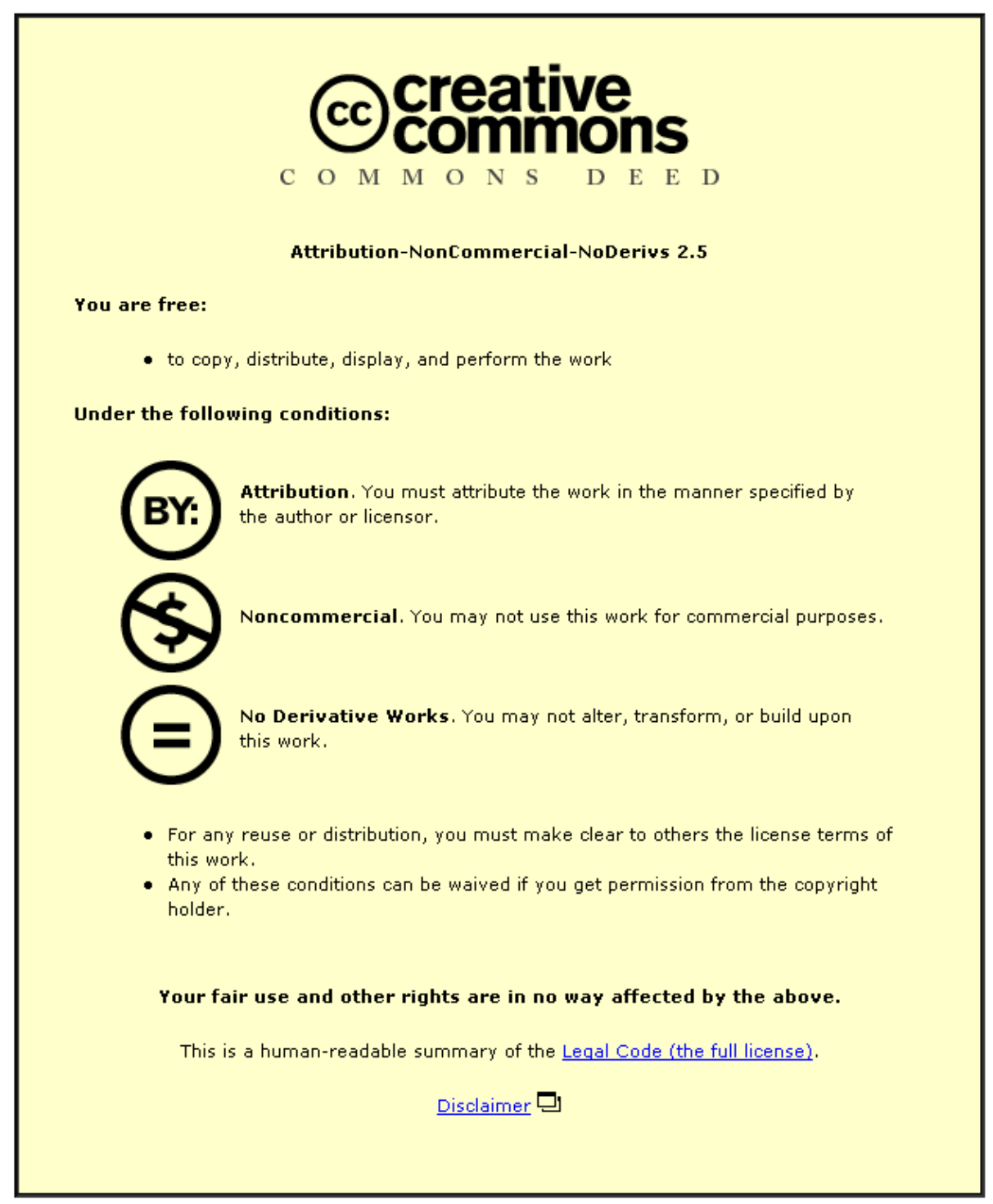

For the full text of this licence, please go to: http://creativecommons.org/licenses/by-nc-nd/2.5/ 


\title{
Mechanical and Electrical Characterisation of Individual ACA Conductor Particles
}

\author{
Guangbin Dou, David Whalley and Changqing Liu \\ Wolfson School of Deformation and Manufacturing Engineering, Loughborough University, Loughborough, Leicestershire, \\ Loughborough University \\ United Kingdom, LE11 3TU. \\ Email: gb.dou@lboro.ac.uk; D.C.Whalley@lboro.ac.uk; C.liu@lboro.ac.uk. Phone: +44(0)1509227677
}

\begin{abstract}
Anisotropic Conductive Adhesives (ACAs) consist of a polymer adhesive matrix containing fine conductive particles. The primary objective of this experimental research is to establish a clearer understanding of the effects of the bonding force on the deformation of individual ACA particles and their resulting conductivity when in contact with an appropriate metallic surface. This has been achieved through simultaneous measurements of the deformation and electrical resistance whilst applying force using a specially configured Nano-indenter machine, where the "indenter", instead of being pointed, had a flat tip about 20-30 $\mu \mathrm{m}$ in diameter. The merit of using this machine is that very small forces, of the order of $100 \mathrm{mN}$, can be accurately applied to the particles to a resolution of $100 n N$ and the resulting deformations, of less than $6 \mu \mathrm{m}$, can then be recorded to a resolution of $0.1 \mathrm{~nm}$. The results showed that the ACA particle deformation was nonlinear and that the force/deformation at which particle crushing occurs was affected by the load rate. The resistance was observed to decrease as the deformation increased up to the crush point at which stage it increased slightly. The voltage versus current behaviour of a deformed ACA particle was also found to be linear.
\end{abstract}

\section{Introduction}

ACAs are conceptually a simple method for achieving high density interconnection of electronic components. They offer other potential advantages in terms of low assembly temperature, being lead free, reduced package size, and compatibility with metallizations unsuitable for use with soldering processes [1]. Whilst unlikely to become a mainstream alternative to soldering for PCB assembly, they are well suited to a number of niche applications, such as chip on board/flex and flat panel display assembly. ACAs are therefore experiencing a significant growth in use, although some aspects of their performance, particularly in terms of yield and reliability, are not yet fully understood. The electronics industry is therefore very interested in the joint reliability of ACA based assemblies. The deformation and conduction properties of the conductor particles are very important and understanding their behaviour will help to improve the packaging process and reveal the mechanisms that cause reliability problems.

The particles used in this experiment were compliant particles. Such particles are generally dispersed randomly in the adhesive matrix at a low density.

It is difficult to measure the deformation of a single ACA particle due to the small particle size and the roughness of the contact area. When considering the function of the particles, two kinds of deformation properties can be identified, i.e. micro properties and macro properties. Micro properties relate to the hardness of the materials constituting the ACA particles, i.e. the particle micro mechanical properties, whilst the macro properties relate to deformation properties of the whole particle.

Previous research on the micro-properties using a nanoindenter on cross-sections of ACA samples assembled at different pressures showed that ACA particle deformation resulted in a reduction in hardness of the polymer core with increasing particle deformation. It also showed that the particle hardness after assembly varied within the particle, due to the non-uniform plastic strain within the particles [2].

The macro-properties of the ACA particles are critical to the ACA material performance, because they determine how the particle deforms and the resulting contact forces with it. However, little research has been conducted into the macro properties of ACA particle deformation, especially for a single particle e.g. $[3,4]$. The reason for this is that the particles are too small to be deformed in normal material testing machines and are also very fragile. Experiments on an individual ACA particle have been conducted [3]. In this experiment, the load versus deformation behaviour was partially measured, however only a modest level of deformation was achieved due to the use of a large punch with a $100 \mu \mathrm{m}$ square flat tip, i.e. about 400 times the area of the particles tested. This resulted in the deformation being insufficient to allow the crushing behaviour to be measured. In another recent study, the load versus deformation behaviour to a very high level of compression was reported, and the load rate effects on the deformation were analysed [4]. These measurement of the deformation properties of individual ACA particles were achieved due to the use of a smaller, specially prepared punch. This paper reports extension of this previous research on the mechanical deformation to also include measurement of the electrical resistance of individual ACA particles undergoing deformation.

In addition to these experimental studies, the deformation properties of single particles have been modelled, for example, using FEA [5] or using an equivalent spring method to simplify the complex deformation situation [6]. This methodology significantly reduces the analysis computer CPU time compared with FE modelling, thereby making ACA process modelling possible.

Previous work has also determined the average mechanical deformation and electrical properties of a large number of ACA particles [7-9]. The difference between these previous studies and the research presented here will be discussed later. 


\section{Materials and Experimental Methods}

\subsection{Materials}

Commercially available ACA particles, $5.75 \mu \mathrm{m}$ in diameter, were used in this research, which were micro spheres of a cross-linked co-polymer resin of di-vinylbenzene coated with $A u$ and $N i$ layers, as shown in Figure 2.

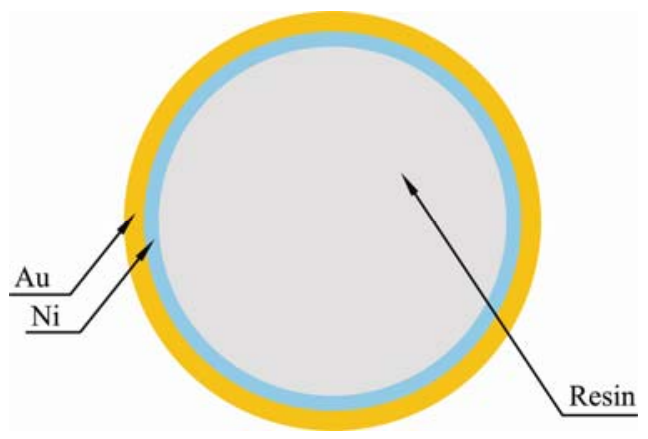

Fig. 2. ACA particle configuration

These particles are specifically designed for use in ACA/ACF applications and have a $\mathrm{Ni}$ layer about $50 \mathrm{~nm}$ thick and a $A u$ layer, less than $30 \mathrm{~nm}$. The metal coating layers on these ACA particles are not homogenous, as shown in Figure 3.

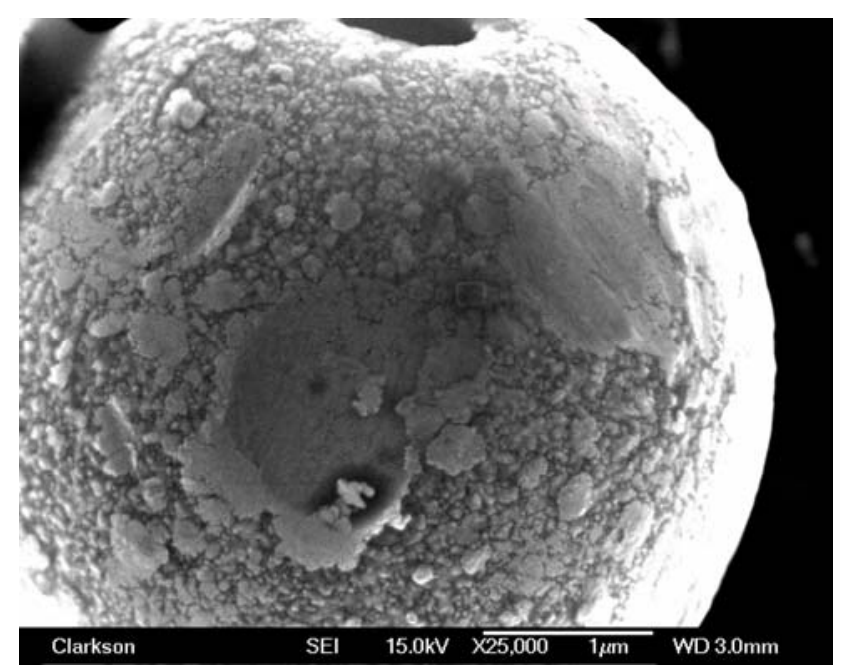

Fig. 3. SEM of a particle

\subsection{Experimental Methods}

\subsubsection{The Nana-indentor}

This experimental research was accomplished using a NanoTest ${ }^{\mathrm{TM}}$ Machine, which is normally used to measure micro materials properties, such as in Nanoindentation Testing, Nano-Scratch Testing and Nanotribometry [10]. However, this machine has been adapted to deform fine particles using a flat tipped punch. The NanoTest pendulum and sample stage are schematically shown in Figure 4, where a flat tipped punch instead of the diamond indenter was used in this experiment. The load resolution of this machine is 100 $n N$, and the displacement resolution is $0.1 \mathrm{~nm}$.

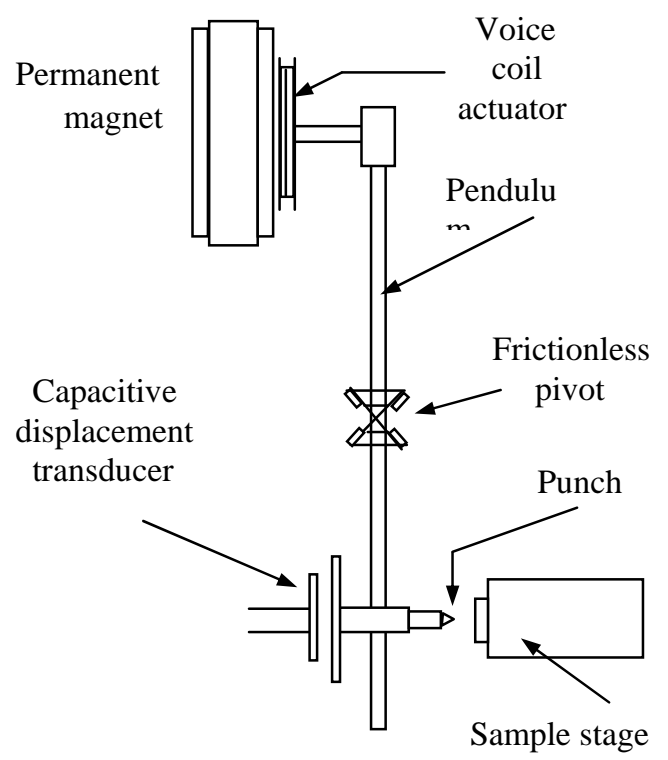

Fig. 4 Schematic diagram of the nanoindentor

The deformation process is schematically shown in Figure 5 , where the base stage is fixed and the punch moves from left to right to deform the particle.

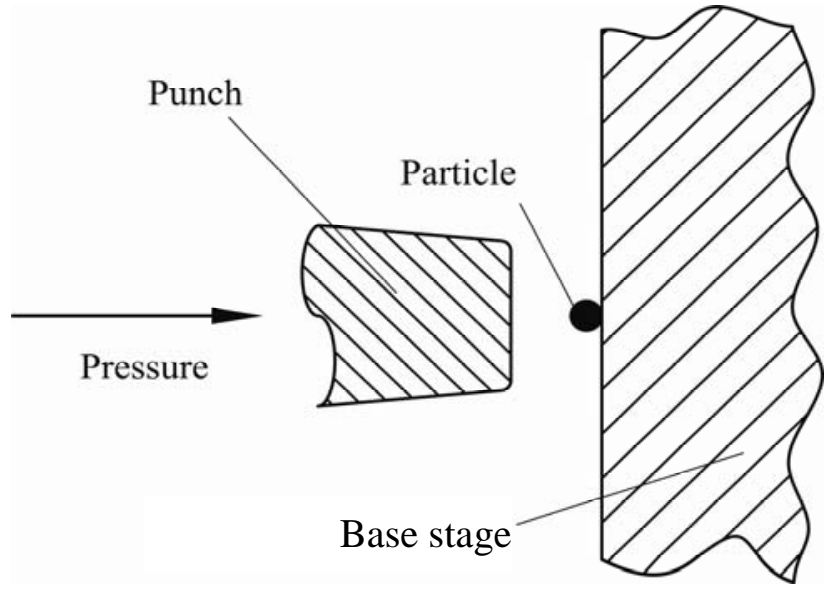

Fig. 5 The particle deformation process

The punch must be aligned before it can deform the particles accurately, because each different punch is a different size, and also the same punch cannot be re-fixed into exactly the same position on the machine in different experiments.

The tests involved force controlled deformation of the particles, where the force was increased linearly with time and the resulting deformation monitored. The load force and the 
deformation were recorded by the nano tester, and then saved in a file in the control computer. They were also acquired through analogue output ports in the indenter machine by a data acquisition system, when the electrical measurements were carried out simultaneously.

\subsubsection{Punch and Base Stage}

In these experiments, the particles were deformed between the punch and the base stage. In order to obtain an accurate measurement of the deformation of the particles, the punch and the base stage must be much harder than the particles, so that the particles do not significantly indent into them. Besides hardness, a good conductivity material is needed for the electrical measurements. Therefore, HSS (high speed steel) and $\mathrm{W} / \mathrm{Cu}$ (W60\%Cu40\%) were evaluated for making the punches, as shown in Figure 6,

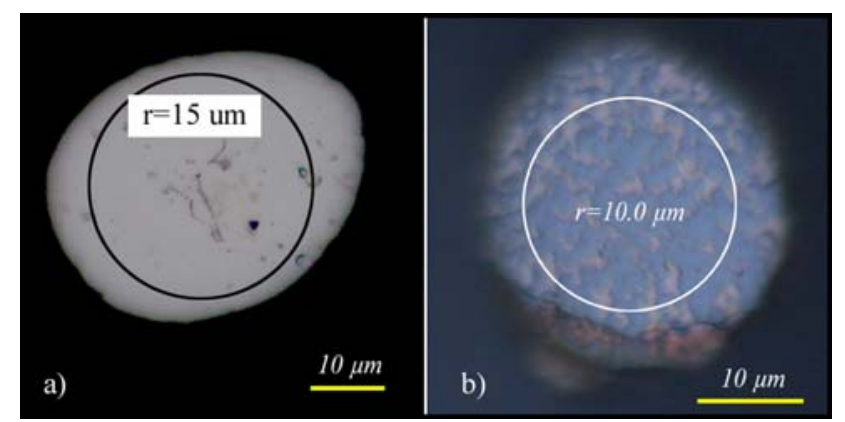

Fig. 6. Needle/punch shape and size

where (a) is a HSS punch head used for the mechanical experiment and (b) is a $W / C u$ punch for the electrical tests. The reason for using HSS for the mechanical deformation tests is that HSS is hard and can be polished to give a very flat and smooth surface with a fairly sharp edge. The reason for using $\mathrm{W} / \mathrm{Cu}$ for the electrical tests is that $\mathrm{W} / \mathrm{Cu}$ is fairly hard whilst has a very low resistivity, although the polished surface achievable was not as good as for HSS and the polished edge was not as sharp, as shown in the figure. Considering the particle size and the required planarity of the punch head surface and the base surface, and also the Nano-indentor resolution, the punch head tips were made with a roughly circular area approximately 20-30 $\mu \mathrm{m}$ in diameter.

The base stage used in the mechanical deformation experiments was a $25 \times 75 \times 1.0 \mathrm{~mm}$ glass microscope slide. In order to readily change between slides coated with different particles, a custom slide holder was used. The microscope slides used were purchased pre-prepared with an extra positive electrostatic charge on the top surface. This resulted in strong adhesion of the particles onto the slide. In order to evenly spread the particles on the slide, the particles were spread gently using lens cleaning paper and an air duster was used to reduce the particle density. For further details of the spreading methods, see reference [4].

A brass plate was used as the base stage for the electrical tests, whose size was $20 \times 55 \times 2.0 \mathrm{~mm}$. To ensure good electrical contact between the ACA particle and the base stage, the surface of the base stage was polished using $1 \mu \mathrm{m}$ diamond powder just before the experiment. In order to readily change between base stages coated with different particles, a custom base stage holder was used.

\subsubsection{Resistance Measurement}

For the electrical tests, an Agilent 34970A Data Acquisition with Agilent 34901A module were used to record the load force, and the deformation depth from the analogue outputs of the NanoTest ${ }^{\mathrm{TM}}$ machine. The Agilent 34901A module was also used for four wire measurement of the electrical resistance of individual ACA particles undergoing deformation with automatic compensation for any thermoelectric EMFs.

A schematic of the electrical test configuration is shown in Figure 7, where $R$ represents the resistance of the deforming ACA particle and the contact resistances between the particle and the contact metal surfaces. $R_{1}$ represents the resistance of the base stage and the connecting wires between the joint area, where the particle is deformed on the base stage, and the current source of the measurement system. $R_{2}$ is an equivalent resistance to $R_{1}$, but in series with the voltage measurement section of the measurement system. $R_{3}$ is the resistance of the punch between the point where the second voltage measurement connection is bonded onto the punch and the bottom surface of the punch tip, and $R_{4}$ is the resistance between the punch and second current source connection.

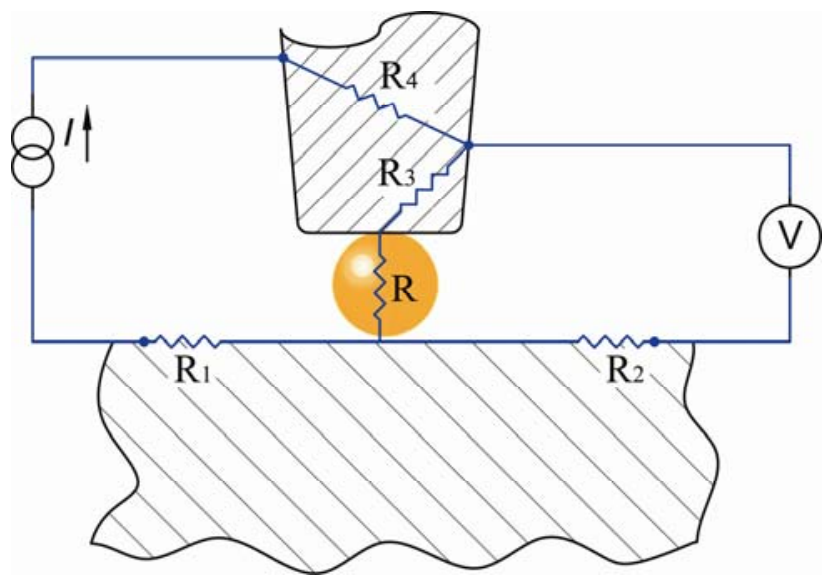

Fig. 7 Schematic of the electrical measurements

The equivalent circuit of the test is as shown in Figure 8, where it can be seen only $R_{3}$ affects the electrical measurement.

The length, $l$, of the metal part of the indentor tip that results in $R_{3}$ is about $400 \mu \mathrm{m}$, the radius of the tip surface is $10 \mu \mathrm{m}$, and the electrical resistivity, $\rho$, of $W / C u$ is $32 \mu \Omega \cdot \mathrm{cm}$. For the indentor tip taper angle of approximately $15^{\circ}, R_{3}$ can be calculated as:

$$
R_{3}=\frac{\rho l}{\pi\left[\frac{r+r+l \tan \left(\frac{15 \pi}{180}\right)}{2}\right]^{2}} \approx 1 \mathrm{~m} \Omega .
$$


Therefore, the effect of $R_{3}$ on the resistance measurements are negligible if the measured resistance is more than 100 $m \Omega$.

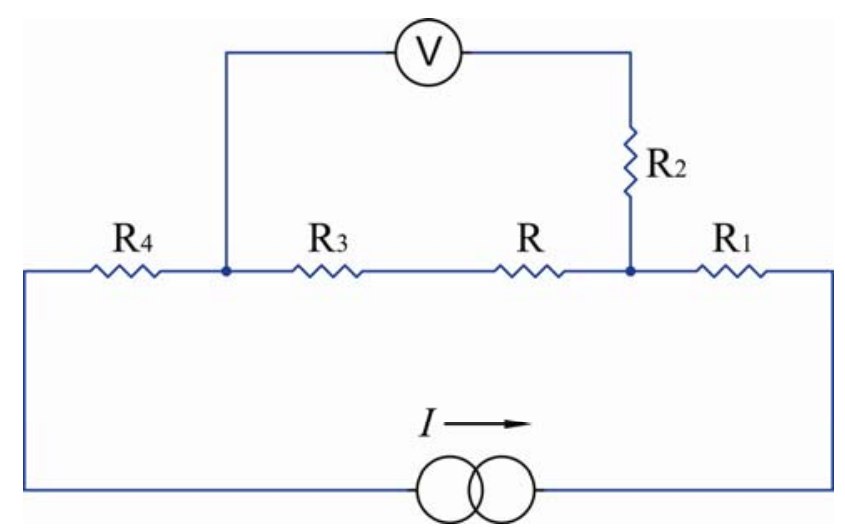

Fig. 8 The equivalent circuit

\subsubsection{Experimental Design and Parameters}

The aim of this experiment was to measure the deformation properties of a single particle versus the load force, the load rate effects on the deformation, and simultaneously the effects on the deformation due to differences in the experiment setup, as well as the electrical properties of an individual particle undergoing deformation.

There were several initial user defined test parameters for the nano tester that affected the final experiment results, which were load rate, maximum force, and depth gain. Load rate is the amount the load force increases per second, which remains constant during each particle deformation test. Depth gain is a machine constant, and is the maximum distance that the machine can move the punch forward. The machine stops increasing load force when the load force reaches the maximum load force, even if the deformation does not exceed the depth gain. Vice versa, the machine stops increasing the load force when the deformation reaches the depth gain, even if the load force is still smaller than the set maximum force.

A set of mechanical experiments were designed and carried out, mainly to explore the effect of the load rate. In total 23 experiments were conducted for the mechanical tests as shown in reference [4]. In order to obtain the deformation of the punch when it indents directly on the glass, one experiment without particles was performed at a load rate of 1 $\mathrm{mN} / \mathrm{s}$, an initial load of $0.2 \mathrm{mN}$, a maximum load of $40 \mathrm{mN}$, and a depth gain of $4.783 \mu \mathrm{m}$.

Five experiments were conducted for the electrical tests, all for a load rate of $1 \mathrm{mN} / \mathrm{s}$, maximum load of $60 \mathrm{mN}$, depth gain of $6.378 \mu \mathrm{m}$ and dwell time of $5 s$.

\section{Results}

\subsection{Mechanical Deformation Results}

The results showed that the maximum force and depth gain had no clear effect on the experiment results if controlled within a reasonable range. Therefore, only the load rate effect is considered in this section. It was also found that the particles were all crushed, as shown in Figure 9. For more details of this experiment, see reference [4].

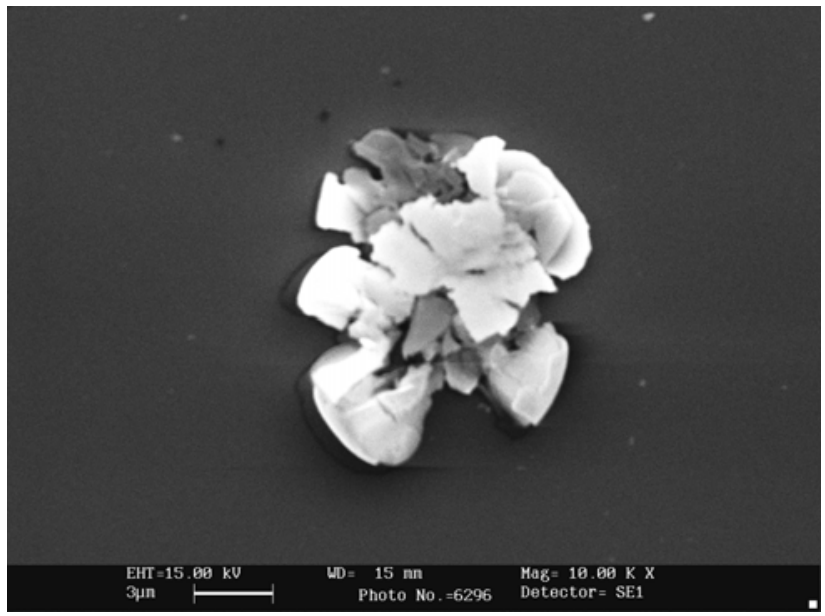

Fig. 9. Example of a crushed particle

\subsubsection{Indentation of the Punch on the Glass Slide}

As stated before, HSS punches and a glass sample stage were used in this experiment. Figure 10 compares the

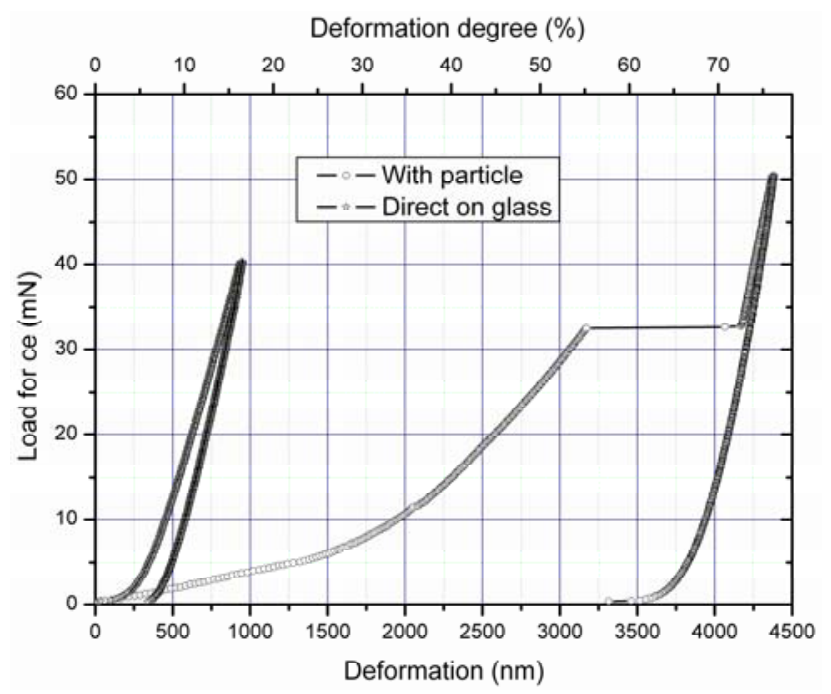

Fig. 10. Comparison of indentation of the punch directly on the glass slide with a particle

indentation of the punch on the glass slide with a typical deformation result for a particle, where the load rate was 1 $\mathrm{mN} / \mathrm{s}$, initial load $0.2 \mathrm{mN}$, maximum load $50 \mathrm{mN}$, and depth gain $6.378 \mu \mathrm{m}$. It shows that the indentation of the punch on the glass was much stiffer, and more linear than the deformation of the particle.

The deformation of the particle also showed much greater plastic deformation than the test directly on glass as shown in the figure, since the particle deformation was more than $3 \mu \mathrm{m}$ and the indentation on the glass was only $0.75 \mu \mathrm{m}$ when the load force was $30 \mathrm{mN}$. This demonstrated that the selection of 
the HSS punch and the microscope slide was suitable for deforming the ACA particles.

\subsubsection{Deformation Versus Load Force Profile}

The profile in Figure 10 shows that the deformation increases gradually as the load force is increased, but the stiffness (load force/deformation) was initially low, i.e. for deformation up to $1.7 \mu \mathrm{m}$, and then increased for deformations greater than $1.7 \mu \mathrm{m}$. There was then a sudden increase in deformation after the deformation reached $57 \%$ of the particle diameter, that is about $3.2 \mu \mathrm{m}$, at which the load force was 32 $m N$. Although the deformation increased by about $2 \mu m$, there was almost no recorded change in the load force, resulting in the horizontal line seen in figure 10 . However, since the machine was operating in a load controlled mode, the load may have actually dropped during the crushing process, but this would have been hidden by the inertia of the pendulum. The load then ramped up until the load force reached its set maximum, followed by the unloading process.

\subsubsection{Experiment Results for Different Load Rates}

Typical load and unload curves for the different load rates are shown in Figure 11.

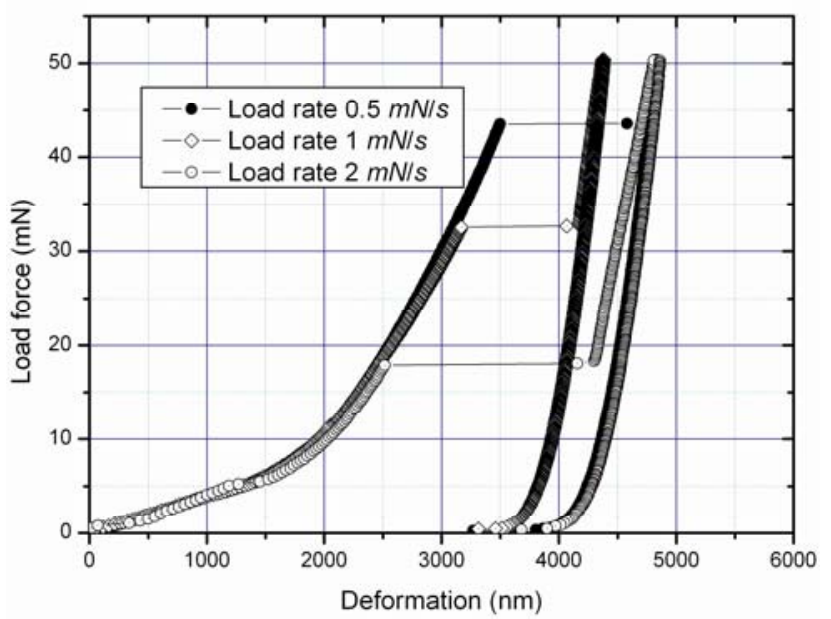

Fig. 11. Comparison between different loading rates

It is assumed that the left side of the horizontal lines in the load profiles indicate the start of particle crushing. This is referred to as the crush point in this work. Figure 11 compares the different loading rates where the results selected are for where the crush load force is near to the mean value for the respective load rate. For the further details of the results for different load rates, see reference [4].

\subsubsection{Particle Crush Point}

The effect of the load rate effect on the particle crush point is shown in Figure 12. The results are for the mean value of the deformation, with the error bars indicating one standard deviation variation.

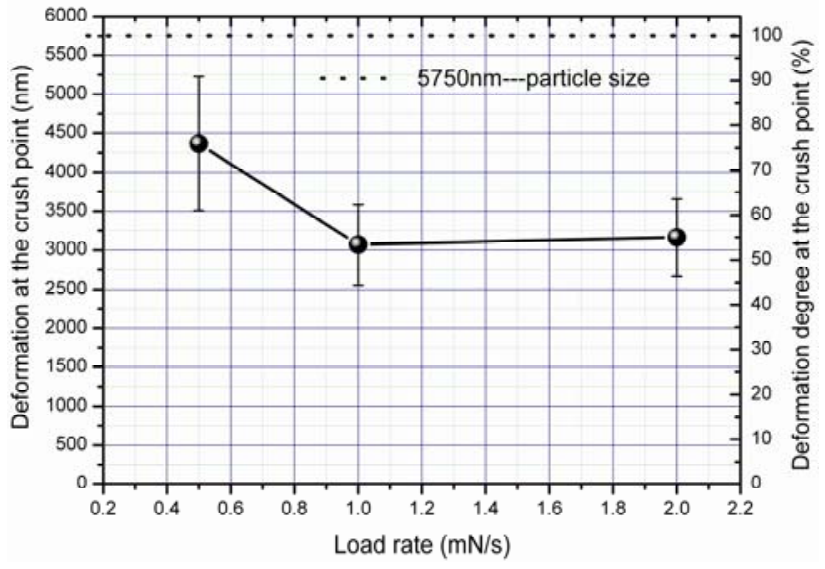

Fig. 12. Load rate effect on the particle crush point

The effect of the load rate on the particle crush force is shown in Figure 13. The results are the mean value of the load force at the crush point, also with one standard deviation shown.

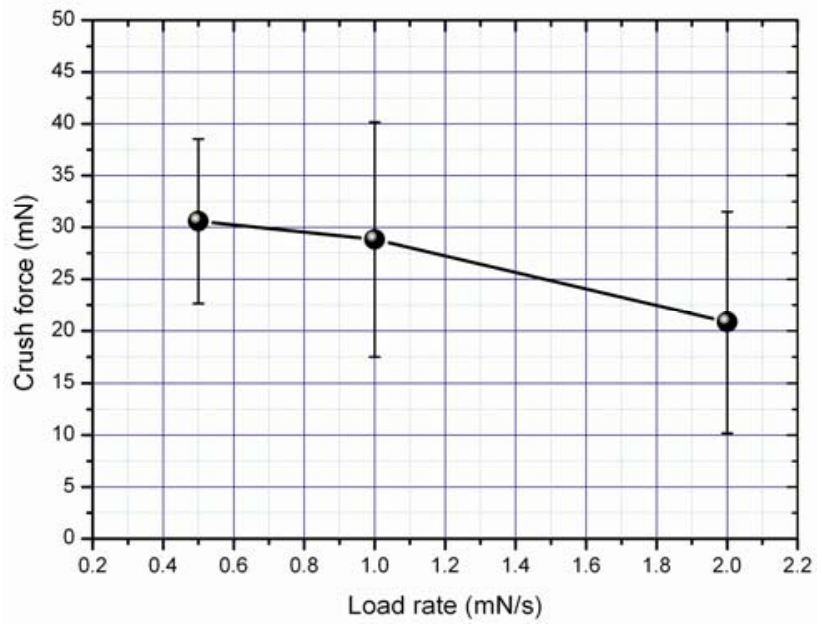

Fig. 13. Load rate effect on the particle crush force

\subsubsection{Particle Stiffness}

The slope of the load versus deformation curve indicates the particle stiffness. The particle stiffness was therefore calculated, as shown in Figure 14, as a moving average over 7 data points in order to reduce short term fluctuations due to the measurement noise. It can be seen that the stiffness increased as the deformation increased, but that at high levels of deformation the rate of increase dropped, indicating that changes in the material behaviour were starting to take place before crushing occurred. 


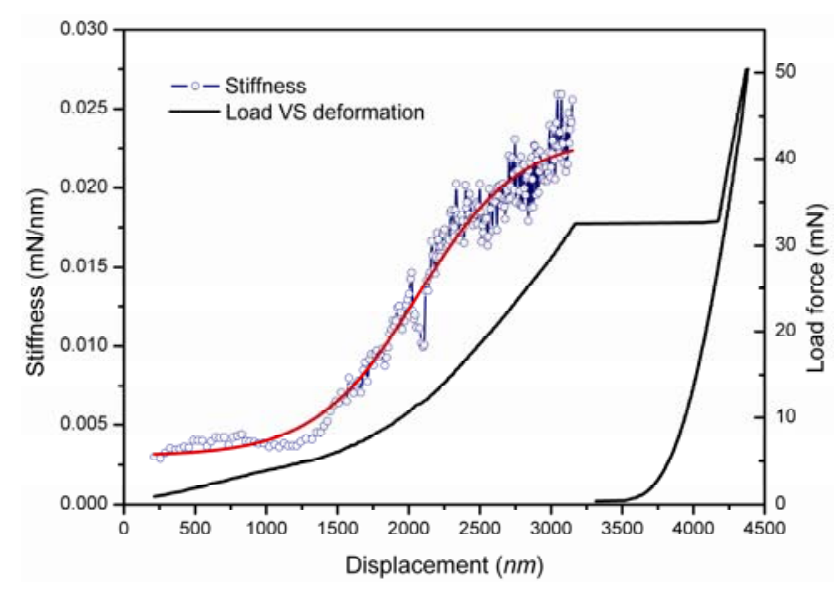

Fig. 14. Stiffness versus deformation

\subsection{Electrical Test Results}

The load force versus time for all 5 tests is shown in Figure 15, where the load and unload rate was $1 \mathrm{mN} / \mathrm{s}$, the maximum load force $60 \mathrm{mN}$, and the dwell time $5 \mathrm{~s}$.

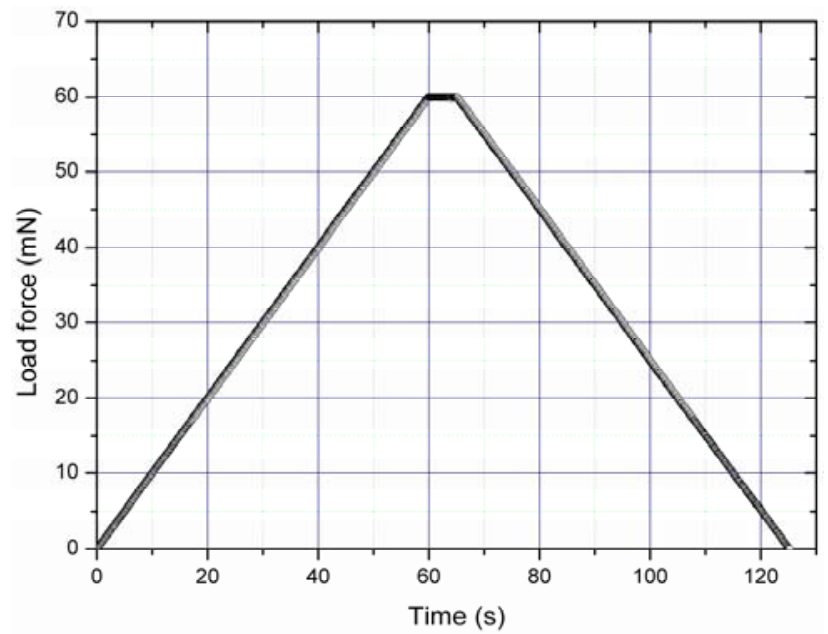

Fig. 15. Load force versus time

In order to provide a detailed understanding of the electrical test results, one test is selected as an example to present in more detail. The load force versus deformation is as shown in Figure 16, where the mechanical deformation is similar to the results measured in the mechanical deformation experiment although $\mathrm{W} / \mathrm{Cu}$ punch was used to achieve the electrical test. It can be seen that the particle started to crush when the deformation reached about $2750 \mathrm{~nm}$, i.e. $48 \%$ of the particle size.

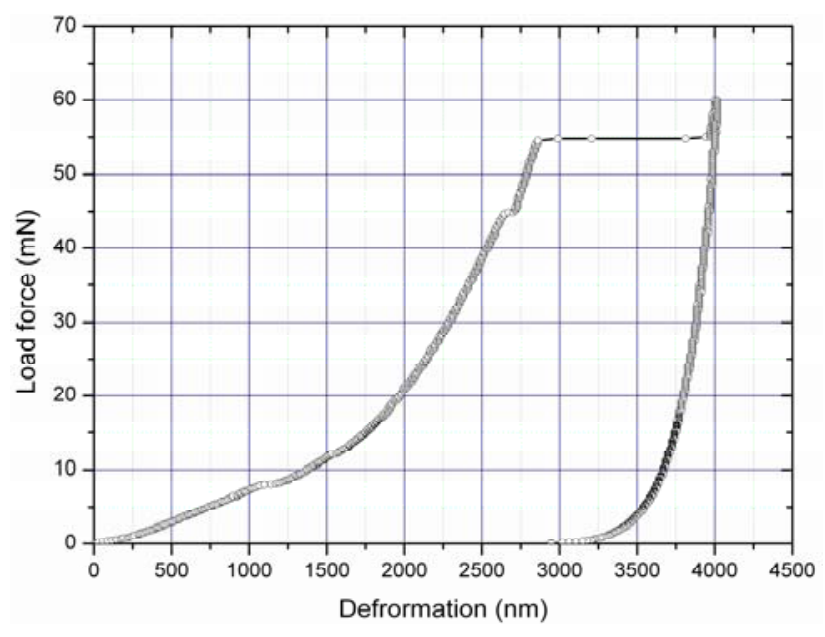

Fig. 16. Load force versus deformation

The resistance versus time is shown in Figure 17, where it can be seen that the joint resistance jumped up when the time was about $55 s$. The abrupt increase in the joint resistance was due to the particle crushing, where the pressure between the contact metal surfaces and the deformed particle was released suddenly. No resistance variation was observed during the dwell period.

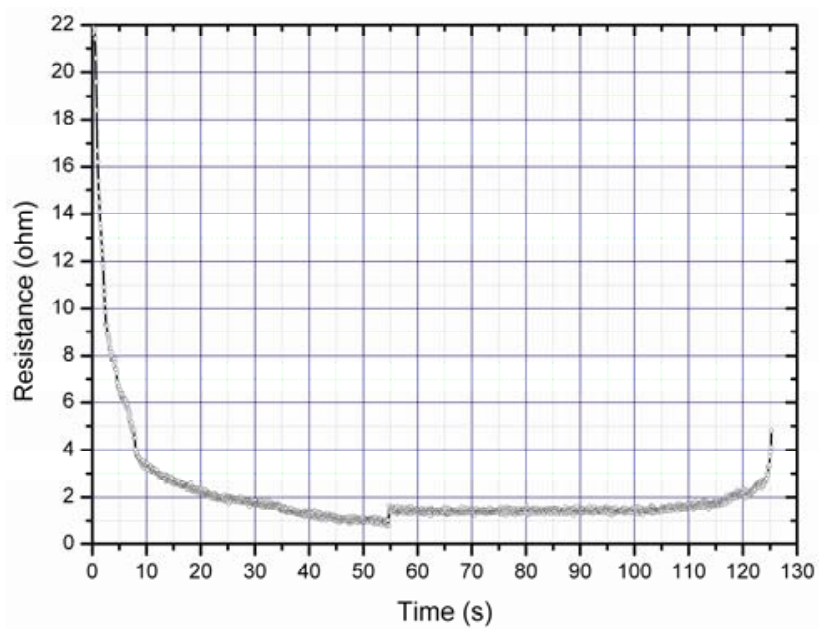

Fig. 17. Resistance versus deformation

The resistance versus deformation is shown in Figure 18, where it can be seen that the joint resistance reduced as the deformation increased until the lowest resistance was measured when the deformation was about $2750 \mathrm{~nm}$, the crush point, after which the joint resistance increased slightly during the crushing deformation. The joint resistance then increased gradually during unloading of the deformation. 


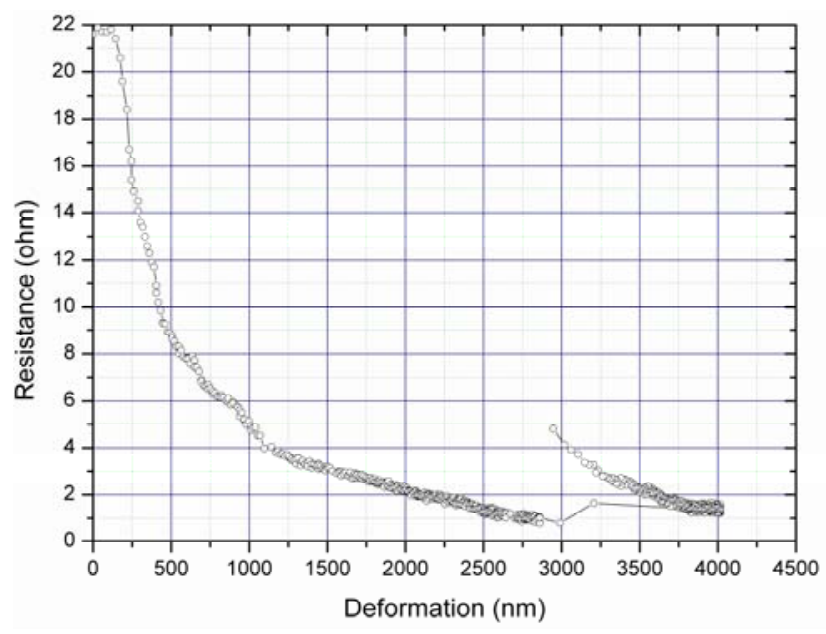

Fig. 18. Resistance versus deformation

The results of the five electrical tests are as shown in Figure 19, from the point of first contact up to the deformation at the crush point (test 2 was the one selected as the typical result shown above.) It can be seen that generally similar resistance versus deformation behaviour was measured, although the start points and the end points were different.

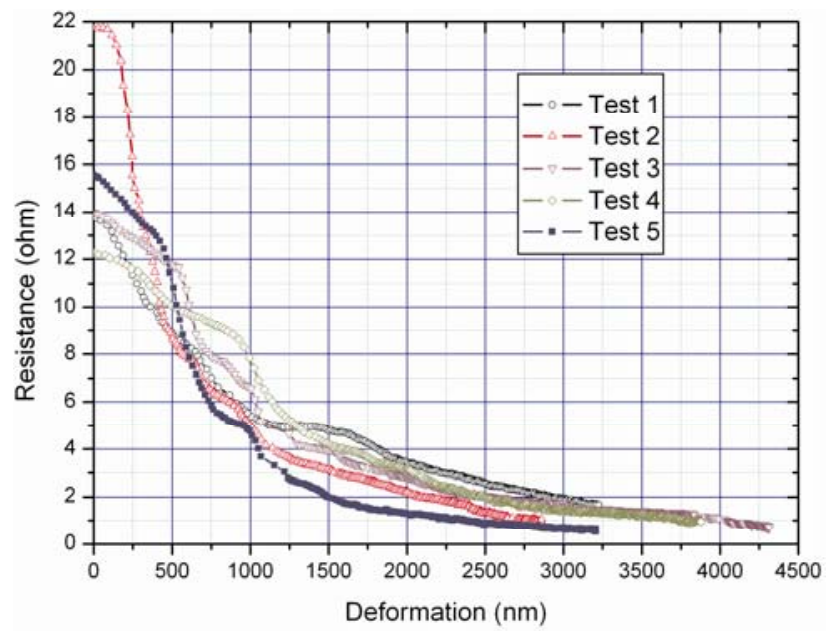

Fig. 19. Results of electrical tests

\subsubsection{Voltage Versus Current Results}

Voltage versus current (V/I) measurements were also conducted. The procedure was that the particle was deformed $2000 \mathrm{~nm}$, i.e. totally about $35 \%$ of the particle diameter, at a load rate of $1 \mathrm{mN} / \mathrm{s}$, and then held at this deformation for 20 minutes, whilst the V/I behaviour was measured.

The current, $I$, was applied using a current source that was manually switched in steps of $0.1 \mathrm{~mA}$, approximately every 10 seconds from $0.1 \mathrm{~mA}$ to $1.6 \mathrm{~mA}$, and then back to $0.1 \mathrm{~mA}$, as shown in Figure 20.

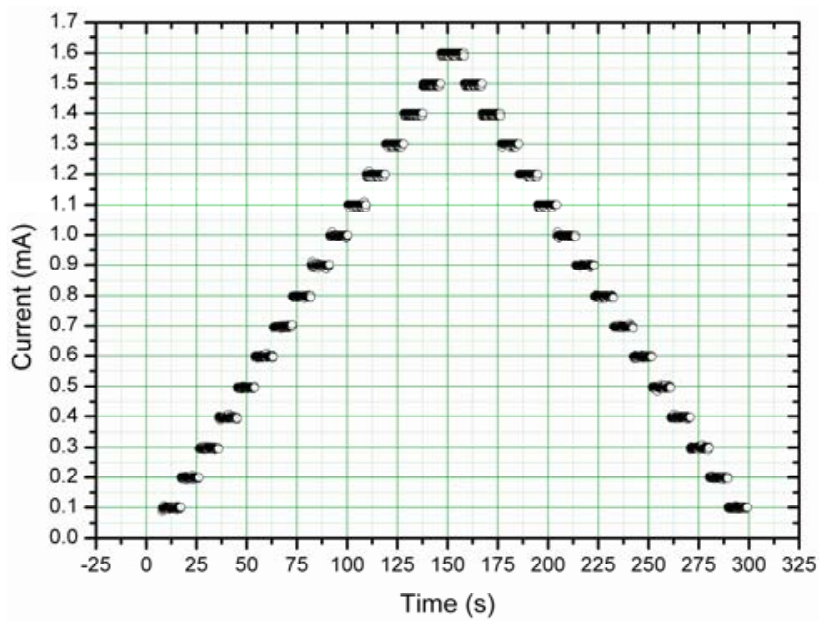

Fig. 20. Applied current versus time

The measured voltage, $V$, is shown in Figure 21. There were some fluctuations in the measured voltages, believed to be due to noise picked up by the data acquisition system and the average voltage measured for each current increment is therefore presented in Figure 21.

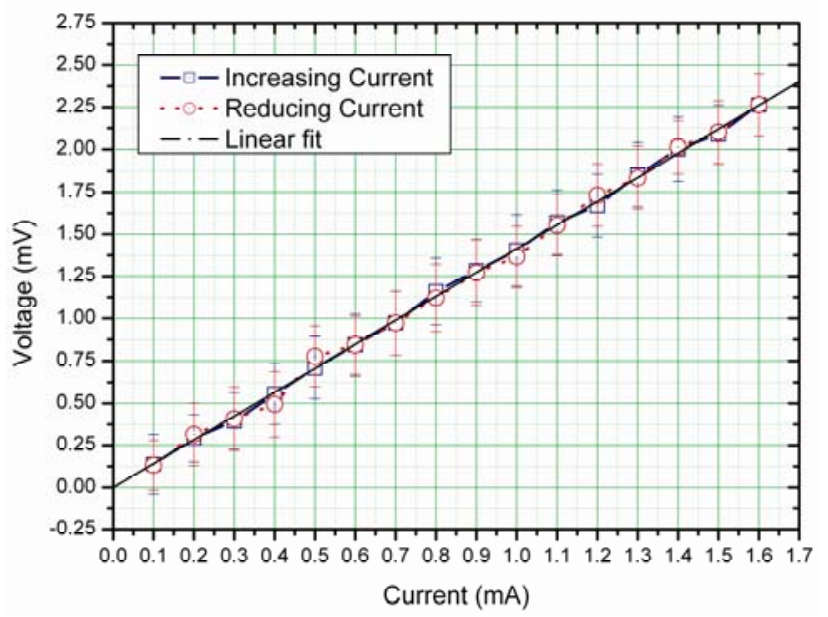

Fig. 21. Voltage versus current

\section{Discussion}

\subsection{The Complexities of the ACA Particle Deformation}

The results of the loading and unloading experiments for single ACA particles suggested that the effects of the test parameters on the particle deformation was complex. This complex behaviour was believed to be caused by the size of the particles, the sphere geometry of the particles, and the materials of the particles. Firstly, the particle size was small, and the surface roughness of the stage, the punch and the particles may have affected the deformation process. Secondly, the particles are not perfect spheres. Deformation of a ball is complex, since the strain is localized in very small areas of the particle when the compression starts, then the materials near the contact point locally deform plastically. 
Finally, the presence of the metal layers also increased the complexity. In the deformation, the situation was firstly the stretching of metal layer, then the initiation and growing of cracks in the metal layer, continually the initiation and growing of cracks in the polymer, the crushing of the particle due to the large deformation. Simultaneously, plastic deformation occurs throughout the whole deformation process. Furthermore, the polymer material of the particle core had visco-elastic nature [1], where the local strain rate (depending on how fast the machine changes the deformation of the particle) was very important. These effects are a combination of geometrical non-linearity (large displacement and contact), and material non-linearity (plasticity, fracture and hardening/softening properties of the polymer core during deformation).

The deformation can be divided into 4 stages:

Stage I: The results, as shown in Figure 10, show that initially the deformation is approximately proportional to the load force applied until the deformation degree reached approximately $30 \%$. The particle stiffness was low during this stage, as shown in Figure 14, because the initial deformation started from a point, and then the point increased into a circular area and grew larger and larger as the load force increased, but was still small compared to the particle diameter. It can be concluded that the deformation was mainly concentrated in the contact area in this step. Especially at the edges of the deforming particle [2].

Stage II: This stage started at about 30\% particle deformation, and continued until it reached about 55\%. The stiffness increased significantly during this stage as shown in Figure 14, since the deformed contact area became larger compared to the particle in the stage I. Therefore, the shape of the deformed particle became more like a deformed cylinder, rather than a sphere, therefore it was much harder than in stage I. However, the stiffness was getting smaller before the particle was crushed as shown in Figure 14, this is believed that small cracks were initialled in the deformation before crushing.

Stage III: In this stage the deformation rapidly increased from about $55 \%$ to around $75 \%$. The very low stiffness during this stage of deformation suggested that the particle was crushing in this step.

Stage IV: In this stage, the particle had been crushed thoroughly, the particle became very hard and had almost no further plastic deformation. The process was that the punch continued to press the particle until it reached the maximum load, then the unload process started.

\subsection{Load Rate Effect on the Particle Crush Point}

Figures 12 and 13 show that the particle deformation and crush force were higher when the load rate was $0.5 \mathrm{mN} / \mathrm{s}$, at which the particles can be deformed by about $3500 \mathrm{~nm}$, or around $60 \%$ of the particle size. However, the crush point deformation dropped to about $52 \%$ of the particle size, about $3000 \mathrm{~nm}$, when the load rate was $1 \mathrm{mN} / \mathrm{s}$. And there was small rise in the deformation when the load rate was $2 \mathrm{mN} / \mathrm{s}$. The dropped deformation was around $2700 \mathrm{~nm}$, about $46 \%$ of the particle size. Therefore, it can be concluded that the load rate affected the particle deformation process, delaying the crushing significantly at lower load rates. This is considered to be due to the visco-elastic properties of the polymer particles. The error bars in the figure suggested that the lower the load rate, the more variable the crush point.

Figure 13 shows that the load force was high, about 31 $m N$, when the load rate was $0.5 \mathrm{mN} / \mathrm{s}$, but that it dropped a little, to less than $30 \mathrm{mN}$, when the load rate was $1 \mathrm{mN} / \mathrm{s}$. Therefore, there was no major difference in the crush load force between load rates of $0.5 \mathrm{mN} / \mathrm{s}$ and $1 \mathrm{mN} / \mathrm{s}$ if only the mean load force was considered. However, the crush load force was more variable at the higher load rate, since the error bar was bigger, as shown in the figure. When the load rate was $2 \mathrm{mN} / \mathrm{s}$, the mean load force dropped to about $20 \mathrm{mN}$, which is more significant than the drop for the load rate of 1 $\mathrm{mN} / \mathrm{s}$, and the error bar was similar to that for the load rate of $1 \mathrm{mN} / \mathrm{s}$. It is suggested that the high load rate $2 \mathrm{mN} / \mathrm{s}$ caused the particles to be more easily broken, as the deformation at crush point was only around $46 \%$ of the particle size, much smaller than the deformation in the load $0.5 \mathrm{mN} / \mathrm{s}$, however a little bit smaller than in the load $1 \mathrm{mN} / \mathrm{s}$, where the deformation was about $52 \%$ of the particle size. Moreover, the lower the load rate was, the higher the stiffness, and the larger the crush load force, as shown in Figure 11.

\subsection{Electrical Properties of Individual ACA Particles}

The results of the electrical tests showed that the electrical properties of individual ACA particles undergoing deformation are variable, although the general shape of the resistance curves were similar. The joint resistance increased when the particle began to crush, as shown in Figure 17. This is believed to be due to the contact pressure between the particle and the metal surfaces dropping suddenly when the particle started crushing. The joint resistance kept steadily reducing before the crush point although the crush points were quite different as shown in Figure 18. The joint resistances that were detected firstly when the deformation started were different. Many factors can affect the first contact resistance, such as the geometry of the particle, the roughness of the contact surfaces, and the micro structure of the punch and the contact metals. It can be seen that the joint resistance of a deformed (to $40 \%$ of the original particle size) ACA particle is about $2 \Omega$ as shown in Figure 18 and 19 .

Ohmic conduction was found in the range of the applied current $(0.1$ to $1.6 \mathrm{~mA})$. The linear resistance was about 1.41 $\Omega$. Normally, there are 20 to 30 particles trapped in each joint of an the actual electronics package, therefore, this individual particle resistance of $1.41 \Omega$ would result in a joint resistance from $47 m \Omega$ to $70 m \Omega$ if the particles are deformed to be about $35 \%$ of their original size.

\subsection{Comparison with Previous Work}

The average mechanical properties of a number of ACA particles were previously measured by compressing many particles between flat plates [7-8]. The particles used in this research were smaller than those studies, e.g. the particles used by Kristiansen et al. were $10 \mu \mathrm{m}$ in diameter. However, the particle deformation results from Kristiansen et al. and Shen were qualitatively similar to the results presented here, although the maximum load per particle applied in those 
studies was insufficient to reach the crush point i.e. only about 2.5-17 $m N$ per particle.

The effect of load rate on ACA particle deformation was not studied in these previous studies. And no electrical testing of individual ACA particles has been found to be reported previously.

\section{Conclusions}

This paper has demonstrated a new technique for the mechanical deformation of a single ACA particle.

The results show that the load force affected the particle deformation, including the load and displacement at the crush point, and the variability of the deformation behaviour. They also show that at a low load rate, greater particle deformation before crushing can be obtained.

The measured individual particle resistance of $2 \Omega$ would equate to a resistance for a typical joint in an ACA assembly, with 20 to 30 particles deformed to about $40 \%$ of the particle size, to be about $67 m \Omega$ to $100 m \Omega$. This result compares well with the results presented in [11], where the average joint resistance was measured to be about $41 \mathrm{~m} \Omega$.

Future work will also measure the recovery (unloading) properties for uncrushed particles and visco-plastic properties of individual particles undergoing deformation.

\section{Acknowledgments}

The authors would like to acknowledge Dr. Helge Kristiansen from Conpart AS, Norway, who provided the ACA particles used in the experiments and the SEM in Figure 3.

\section{References}

1. Liu, J., Conductive Adhesive for Electronics Packaging. 1999, Port Erin, Isle of Man, British Isles: Electrochemical Publications Ltd.

2. Fu, Y., Wang, Y. L., Wang, X. T., Liu, J. H., Lai, Z. H., Chen, G. L. and Willander, M., "Experimental and theoretical characterization of electrical contact in anisotropically conductive adhesive," IEEE Transactions on Advanced Packaging, 2000, 23(1): p. 15-21.

3. Kwon, W.-S. and Paik K.-W., "Experimental Analysis of Mechanical and Electrical Characteristics of Metal-Coated Conductive Spheres for Anisotropic Conductive Adhesives (ACAs) Interconnection," IEEE Transactions on Components and Packaging Technologies, 2006, 29(3): p. 528-534.

4. Dou, G.B., Whalley, D.C. and Liu, C.Q., "Deformation Property Measurement for Single Anisotropic Conductive Adhesive Particles," 1st Electronics Systemintegration Technology Conference (ESTC), 2006, Vol II, Dresden, p. 840-847.

5. Zhang, Z.L., Kristiansen H. and Liu , "A method for determining elastic properties of micron-sized polymer particles by using flat punch test," Computational Materials Science, In Press, Corrected Proof, Available online 8 August 2006.

6. Chiang, K.N., Chang C.W. and Lin C.T., "Process modeling and thermal/mechanical behavior of ACA/ACF type flip-chip packages," Journal of Electronic Packaging, 2001, 123(4): p. 331-337.

7. Kristiansen H., Brudberg U. and Gulliksen M, "Electrical and Mechanical Properties of Metal-coated Polymer Spheres for Anisotropic Conductive Adhesive," The Second IEEE International Symposium on Polymer Electronics Packaging, 1999, Gothenburg, Sweden, p.6371.

8. Shen, Y., "Mechanical Properties of Conductive Particles for Anisotropic Conductive Adhesive (ACA)," A Master Thesis in Material Science and Engineering, Chalmers University of Technology.

9. Ogunjimi A. O., Mannan S.H., Whalley D.C. and Williams D.J., "The Assembly Process for Anisotropic Conductive Joints - Some New Experimental and Theoretical Results," Journal of Electronics Manufacturing, Vol 5, No. 4, Dec,1995, p. 263-271.

10. http://www.micromaterials.co.uk

11. Dou, G.B., Whalley D.C. and Liu C.Q., "The effect of coplanarity variation on Anisotropic Conductive Adhesive assemblies," Proceedings of 56th Electronic Components \& Technology Conference 2006, Vol 1, 2006, p. 932-938. 